\title{
Analysis of Knowledge Base Units within Standardized Electrical Engineering Subfields
}

\section{Živadin Micié, Momčilo Vujičić, Vera Lazarević}

Faculty of Technical Sciences, University of Kragujevac

Svetog Save 32, Čačak, Serbia

micic@kg.ac.rs, momcilo.vujicic@ftn.kg.ac.rs, vera.lazarevic@ftn.kg.ac.rs

\begin{abstract}
The paper presents a comparative and multicriteria statistical analysis of knowledge base units as shown on the examples of standardized subfields of electrical engineering. A number of objectives have been realized on knowledge pathways, both globally and locally, and initial hypotheses have been confirmed. Ranking/clustering among standardized fields and subfields has been carried out based on time-frequent innovations presented by knowledge base unit quantities and values. Web applications for analysis and singling out of samples from the entire Web-population of local (SRPS) and global (ISO) standardization have been developed and implemented. These applications represent a significant contribution to authenticity, particularly the authenticity of statistical research methodology.

Original regression equations with accompanying indices of quantity, knowledge base unit values and ranking have been developed on the examples within the field of electrical engineering. Results of this study enable the realization of some higher practical objectives, i.e., (1) modification of teaching subjects and improving educational and financial resources for the quality of knowledge, (2) ranking of both narrow and broad standardized technologies and scientific fields.
\end{abstract}

Keywords: electrical engineering; knowledge; standardization; SRPS; ISO; subfield

\section{Introduction}

\subsection{What Problem Does the Paper Look at?}

The paper looks at the comparative and multicriteria analysis and evaluation of the international (ISO/IEC) and local (SRPS - designation of standard in Serbia, [1]) knowledge in the subfields of electrical engineering. In this particular field, knowledge pathways differ from other standardized fields of human endeavour. In this field more importance is given to local and individual rather than collective knowledge. According to the international classification of standards (ICS_1), 
electrical engineering is classified as field XXIX and it consists of 19 subfields (ICS_2 = 29.xyz, [2]): 29.020 - Electrical engineering in general, including voltages, general electrical terminology, electrical documentation, electrical tables, safety, fire hazard testing, etc. (electrical diagrams and charts, electrical power stations, electromagnetic compatibility), 29.030 - Magnetic materials, 29.035 - Insulating materials, 29.040 - Insulating fluids, 29.045 Semiconducting materials, 29.050 - Superconductivity and conducting materials, 29.060 - Electrical wires and cables, 29.080 - Insulation, insulating fluids, insulating materials, insulating fluids, 29.100 - Components for electrical equipment, 29.120 - Electrical accessories, 29.130 - Switchgear and controlgear, 29.140 - Lamps and related equipment, 29.160 - Rotating machinery, 29.180 Transformers, reactors, instrument transformers, 29.200 - Rectifiers, converters, stabilized power supply, including semiconductor converters, 29.220 - Galvanic cells and batteries, 29.240 - Power transmission and distribution networks, electricity supply systems in buildings, 29.260 - Electrical equipment for working in special conditions, 29.280 - Electric traction equipment, including railway electric fixed installations, electric road vehicles, non-electric railway tractive stock.

\subsection{Why Has the 'Problem' Not Been Solved Before?}

In the investigated field of electrical engineering, the 'problem' has been observed only in the past five years (2008 to 2012); e.g. in 2010 two local-scale standards (SRPS) were published daily! The same trend continued in 2011 and 2012. Currently, it is the field of electrical engineering that encompasses the greatest number of SRPS samples. Particularly important and significant are alternative solutions to the 'problem' of individual access to the knowledge base units. This is particularly important in various environments, institutions and corporations in developing countries. It is of great importance to provide organized help and support to teachers and assistants in order to achieve mass education based on the platform of standardization. Solving this 'problem' at the state level leads to a national model of e-learning excellence. Although, according to [3], the 'Quality is free' philosophy was prevalent in the previous century, nowadays, standards are extremely costly.

\subsection{The Research Objectives}

The initial hypotheses and research objectives in the field of electrical engineering provide opportunities for:

1 ( $\mathrm{P}$ - Plan) resource planning, i.e. conducting comparative analyses and 'selection' of regression equations of the closest realities with explicit mathematical relations, with the aim of predicting the future resources and comparing them with the trends developing in other areas; 
2 (D - Do) determining clear correlations in space and time, collectively and locally (ISO and SRPS), with annual trends of innovating the valued standardized knowledge base units;

3 (C - Check) checking and conducting multicriteria analyses of standardized knowledge base units by defining the comparative indices (quantity, value and ranking) of individual subfields, the field in its entirety and the future establishing of appropriate relations with scientific fields and the related teaching subjects at a higher education level;

4 (A - Act) deriving alternative solutions in order to replace discontinuous with continuous (cumulative) knowledge innovation, especially of teachers and the staff, but also of all the users in the related subfields.

\section{Research Methodology and Framework}

The PDCA (Plan, Do, Check, Act) statistical methodology of dynamic analyses and deductive-inductive reasoning methods has been used for predicting the future development and innovation of the pragmatic framework. Methodologically, statistical indices have been formed for the comparison of ISO-SRPS relations in the field of electrical engineering (ICS_1 = 29) with other fields of human endeavour, including: Quantity indices (Iq), value indices (Iv) and ranking index (Iqv). Quantity indices (Iq), defined and determined for both ISO and SRPS, refer to the following: Samples (Iqs), published standards (Iqp), standards under development (Iqu), standards withdrawn from use (Iqw), deleted projects (Iqd), innovations in various stages of development $\left(\mathrm{Iqi}=\mathrm{Iqu}_{/ 2012}\right)$ - for the entire previous calendar year.

Value indices (Iv) are in correlation with quantity indices, whereby the results are graphically presented both cumulatively and by trends, within the majority of the 19 electrical engineering subfields, shown by figures consisting of two parts, (a) including time aspects for the entire research period - by years of publication, i.e., $\sum \mathrm{Iv} / \mathrm{year}$, as well as (b) including regression trend lines (exponential, linear, logarithmic and polynomial), based on data collected over the previous five years (2008 to 2012) and by the determined regression equations $\mathrm{y}_{\mathrm{i} / \text { SRPS }}$, Ivi/year.

For the complete 'game' (browsing, analysis, systematization and presentation of the results), original Web applications have been used for research purposes, as examples of IT innovations of software products on comparative samples in the fields of electrical engineering (for ICS_1 = 29), and on the ISO and SRPS levels. The first Web application gathers (and analyses) data on the local SRPS standardization level (Iqs/SRPS/2012.01 $\approx 34000$ local 'innovation', [1]) and sample of $\mathrm{IqS}_{/ 29 / \mathrm{SRPS} / 2012.01}=2111$ units). The second Web application browses (analyses) the ISO standardized unit base $\left(\mathrm{Iqs}_{/ / \mathrm{ISO} / 2012.01} \approx 42000\right.$ collective-global innovations on the examples of standards [2]) and the sample of Iqs/29//SO/2012.01 $=55$ units. 
Multicriteria analysis is used to extract and evaluate the results achieved so far, both at the beginning and at the end of the year (01/2012, 11/2012 and 12/2012, Table 1). Indices of quantity, value and ranking allow comparisons within the examined field and the subfields, along with time-line based comparisons and external comparisons with other fields. This methodology enables the investigation and comparison of the results with those in other areas of work and human endeavour - as presented in [4].

\section{Results}

\subsection{Comparative Analysis and Clustering}

The results of the analysis of standardized knowledge base units within the field of electrical engineering are presented by comparative indices of quantity and value for each of the 19 subfields and the field as a whole (Table 1). Further, statistical samples (Iqs) with the accompanying comparative results and other indices of quantity and value are used to present the analysed knowledge parameters, as shown in Table 1.

Columns 7, 8 and 11 in Table 1 refer to SRPS, i.e., the current state of SRPS development, the sum of newly developed SRPS in 2012 and values based on the most appropriate regression equations singled out, respectively ((1.1) to (20.1)). In early 2012, SRPS standards (drafts) were developed faster than the ISO ones by some $300 \%$. As for the value, a similar trend was recorded, as shown in Table 1, columns 12 and 13. CHF stands for the ISO-selling currency (in Switzerland).

Based on Table 1 (Iq, Iqs, Iqp, Iv, EIv/year, yi/year+1), the field of electrical engineering, ICS_1 $=29$, is classified in group VII (ranking index Iqv $=1,2,3$ to 7) and, from the standpoint of higher education, it could/should be classified as an individual scientific field [5]. The quantitative criterion (Iqu/year) applies only to the assessment/evaluation of the innovation and clustering of sub/fields based on the development of SRPS, while regarding the ISO development, the criterion is replaced with Iqu.

The results of the analysis are presented in graphs, including only the subfields belonging to the second and higher groups. The graphs include two parts:

a) Aggregate analyses of all current standards (Std), corrections (Cor), amendments (Amd) and development projects,

b) Financial trend lines, only for Std, not including the period before 2008 (Figures 1 to 17).

In order to present the graphic results more clearly, only analyses by subfields are shown in detail, while the analyses by sub/subfields (62) are not included. 
Table 1

Comparative elements of knowledge pathways ISO-SRPS

(For ICS_1 = 29, 2012 / January-December)

\begin{tabular}{|c|c|c|c|c|c|c|c|c|c|c|c|c|}
\hline \multirow{3}{*}{ I } & \multirow{2}{*}{$\begin{array}{l}\text { Sub/ } \\
\text { field }\end{array}$} & \multirow{2}{*}{\multicolumn{2}{|c|}{$\begin{array}{c}\text { Samples } \\
\text { Iqs }\end{array}$}} & \multirow{2}{*}{\multicolumn{2}{|c|}{$\begin{array}{c}\text { Published } \\
\text { Iqp }\end{array}$}} & \multirow{2}{*}{\multicolumn{2}{|c|}{\begin{tabular}{|c|} 
Developed \\
Iqu \\
\end{tabular}}} & \multirow{2}{*}{\multicolumn{2}{|c|}{\begin{tabular}{|c|} 
Withdrawn \\
Iqw \\
\end{tabular}}} & \multirow{3}{*}{$\begin{array}{c}\text { Trend } \\
\mathbf{y i} / \mathbf{2 0 1 3} \\
\text { CHF }\end{array}$} & \multirow{2}{*}{\multicolumn{2}{|c|}{$\begin{array}{c}\text { Ivalues (CHF) } \\
\sum \mathbf{I v} / \mathbf{2 0 1 2}\end{array}$}} \\
\hline & & & & & & & & & & & & \\
\hline & ICS & ISO & SRPS & ISO & SRPS & SRPS & 2012 & ISO & SRPS & & $\sum \mathrm{Iv} /$ iso & $\sum \mathrm{Iv} / \mathrm{srps}$ \\
\hline 1) & 2) & 3) & 4) & 5) & 6) & 7) & 8) & 9) & 10) & 11) & 12) & 13) \\
\hline 1 & 29.020 & - & 194 & - & 152 & 12 & 44 & - & 30 & 1152 & - & 5871 \\
\hline 2 & 29.030 & - & 19 & - & 19 & 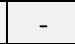 & 10 & - & - & 0 & - & 462 \\
\hline 3 & 29.035 & - & 299 & - & 266 & - & 40 & - & 33 & 1210 & - & 6691 \\
\hline 4 & 29.040 & - & 60 & - & 53 & - & 7 & - & 7 & 97 & - & 1635 \\
\hline 5 & 29.045 & - & 1 & - & 1 & - & - & - & - & 0 & - & 57 \\
\hline 6 & 29.050 & - & 15 & - & 15 & - & - & - & - & 0 & - & 447 \\
\hline 7 & 29.060 & - & 353 & - & 302 & 6 & 53 & - & 45 & 627 & - & 8930 \\
\hline 8 & 29.080 & - & 88 & - & 73 & 1 & 4 & - & 14 & 53 & - & 2541 \\
\hline 9 & 29.100 & - & 55 & - & 55 & - & 1 & - & - & 20 & - & 1291 \\
\hline 10 & 29.120 & - & 257 & - & 215 & 8 & 26 & - & 34 & 402 & - & 8336 \\
\hline 11 & 29.130 & - & 118 & - & 107 & 1 & 26 & - & 10 & 337 & - & 4743 \\
\hline 12 & 29.140 & - & 448 & - & 327 & 1 & 64 & - & 120 & 1090 & - & 12293 \\
\hline 13 & 29.160 & 35 & 76 & 17 & 53 & 12 & 3 & 17 & 11 & 149 & 1492 & 2336 \\
\hline 14 & 29.180 & 7 & 109 & 4 & 96 & 3 & 8 & 2 & 10 & 96 & 348 & 2746 \\
\hline 15 & 29.200 & - & 51 & - & 44 & 1 & 6 & - & 6 & 47 & - & 2041 \\
\hline 16 & 29.220 & 6 & 48 & 2 & 46 & - & - & 4 & 2 & 0 & 200 & 1388 \\
\hline 17 & 29.240 & - & 120 & - & 113 & 2 & 32 & - & 5 & 862 & - & 4227 \\
\hline 18 & 29.260 & 5 & 113 & 2 & 95 & 3 & 35 & - & 15 & 1254 & 238 & 4079 \\
\hline 19 & 29.280 & - & 62 & - & 57 & - & 8 & - & 5 & 170 & - & 1536 \\
\hline XII & $\sum 29$ & 53 & 2486 & 25 & 2089 & 50 & \begin{tabular}{|l|}
367 \\
\end{tabular} & 23 & 347 & 6226 & 2278 & 71651 \\
\hline $\mathrm{XI}$ & $\sum 29$ & 53 & 2479 & 25 & 2060 & 88 & 345 & 23 & 326 & - & 2278 & 61906 \\
\hline $\mathrm{I}$ & $\sum 29$ & 55 & 2111 & 26 & 1837 & 187 & 0 & 23 & 87 & 7695 & 2352 & 51580 \\
\hline
\end{tabular}

In Table 1, the sign $\Sigma$ is not a mathematical "summation function", but a graphical symbol that indicates the cumulative values of some parameters, such as: $\sum$ Ivalues, $\sum \mathrm{Iv} / 2012, \sum \mathrm{Iv} /$ iso, $\sum \mathrm{Iv} /$ srps and $\sum 29$ for $\sum 29 . x y z$.

\subsection{Knowledge Trends Analysis by Subfields}

\subsubsection{Subfield - Electrical Engineering in General (29.020)}

Electrical engineering in general subfield belongs to cluster VI (Iqv $=6$, as well as subfield 3, according to the criteria Iq and Iv, Table 1). The level of this subfield includes: $1^{*}$ voltages, general electrical terminology, electrical documentation, electrical tables, safety, fire hazard testing, $2 *$ electrical diagrams and charts, $3 *$ electrical power stations, $4 *$ electromagnetic compatibility. 
In this subfield, out of the relevant 164 SRPS (Iqp + Iqu) standards, i.e., published + developed standards (value of $\operatorname{Iv}_{(\mathrm{p}+\mathrm{u}) / 29.020 / \mathrm{SRPS}}=5,075.87 \mathrm{CHF}$ ), a significant number of standards were withdrawn $\left(\mathrm{Iqw}_{/ 29.020 / \mathrm{SRPS}}\right)$ and a number of projects were under development - drafts $\left(\mathrm{Iqu}_{/ 29.020 / \mathrm{SRPS}}\right.$, in value $\mathrm{Ivu}_{/ 29.020 / \mathrm{SRPS} / 2012.11}=$ 427.78 CHF).

According to the number of samples (Iqs), one of the most extensive and most representative of the five electrical engineering subfields is presented in Figure 1, along with the results of the analysis of local (SRPS) knowledge standardization.

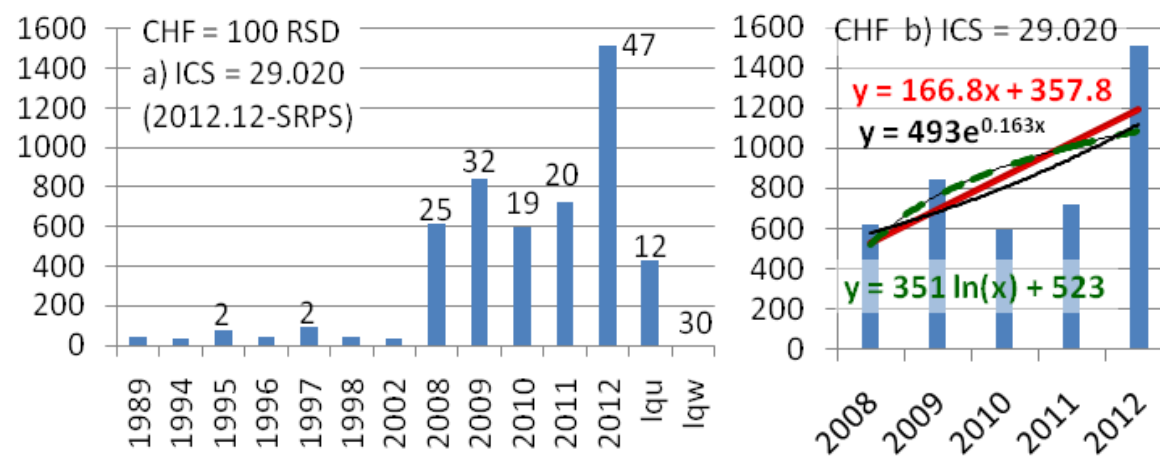

Figure 1

Analysis results for ICS_2 $=29.020$ - Electrical engineering in general - SRPS

Figure 1 includes: a) aggregate analyses, over 1989-2012, and b) the trend of planned (future) annual needs according to the relation (1.1):

$\mathbf{y}_{29.020 / S R P S / 2008-2012.12}=351 \ln (\mathbf{x})+523$.

\subsubsection{Subfield - Magnetic Materials (29.030)}

Magnetic materials subfield belongs to cluster I (Iqv = 1, Table 1). This subfield does not involve any documents under development - drafts (Iqu), or any documents that were withdrawn (Iqw) or deleted (Iqd). Other results can be represented: a) graphically, although the sample of all available Iqs $/ 29.030 /$ SRPS $=19$ from the period of 2010-2011 is insufficient for a detailed statistical analysis; b) with the trend of planned future needs, according to the relation (2.1):

$\mathrm{y}_{29.030 / \mathrm{SRPS} / 20010-2012}=\mathbf{1 0 2 . 2} \mathrm{x}-\mathbf{5 0 . 5 5}$.

\subsubsection{Subfield - Insulating Materials (29.035)}

Insulating materials subfield belongs to cluster VI (as well as subfield 1).

The samples available for analysis at this level involve 12 units, whereas the remaining 287 are distributed among the levels classified according to ICS_3: 29.035.01 - Insulating materials in general (121), 29.035.10 - Paper and board 
insulating materials (32), 29.035.20 - Plastics and rubber insulating materials, including adhesive tapes (114), 29.035.30 - Glass and ceramic insulating materials (6), 29.035.50 - Mica based materials (10), 29.035.60 - Varnished fabrics (2) and 29.035.99 - Other insulating materials (2).

SRPS standardization analysis is presented graphically in Figure 2:

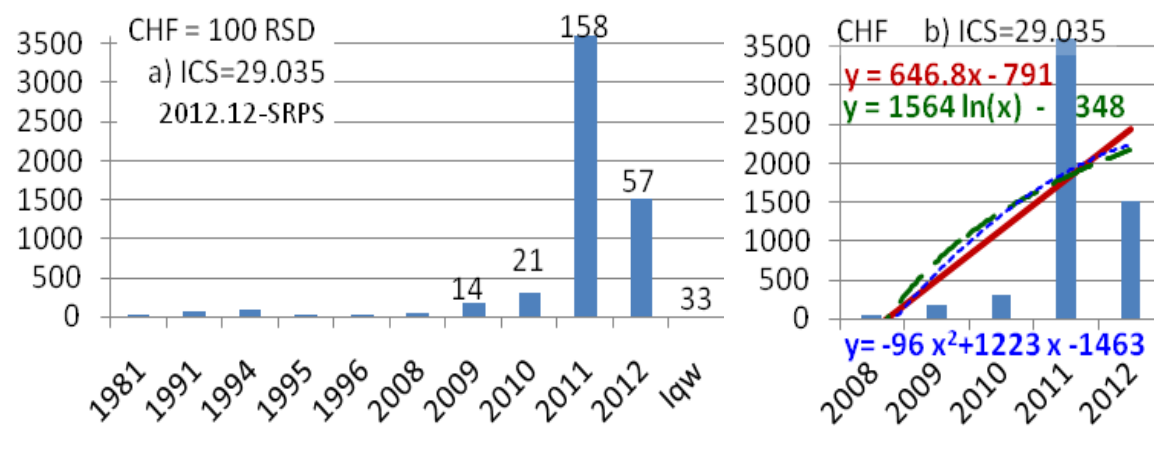

Figure 2

Analysis results for ICS_2 $=29.035$ - Insulating materials - SRPS

Figure 2 includes:

a) the current standards published over 1981-2012, with a significant number of standards withdrawn from use (Iqw, Figure 2a),

b) a trend-line of planned (annual) future needs, i.e., the regression line, which is of a more theoretical nature, as the number of publications $\left(\operatorname{Iqp}_{/ 2011}=172\right)$ in 2011 shows a decreasing trend, whereby the planned values have been obtained using logarithmic or polynomial relation (3.1) (Figure 2b):

$\mathrm{y}_{29.035 / \mathrm{SRPS} / 2008-2012.12}=-96 \mathrm{x}^{2}+1223 \mathrm{x}-1463$.

\subsubsection{Subfield - Insulating Fluids (29.040)}

Insulating Fluids subfield belongs to cluster II ( $\mathrm{Iqv}=2$, along with subfields 9, 16 and 19). This subfield level has one standard, whereas the other 59 are distributed among levels classified according to ICS_3: 29.040.01 - Insulating fluids in general (1), 29.040.10 - Insulating oils (24), 29.040.20 - Insulating gases (34) and 29.040.99 - Other insulating fluids (0).

The results of the standardization analysis in this subfield are presented in Figure 3, including:

a) all analysed samples developed over 1991-2012,

b) a trend of planned needs according to the relation (4.1):

$\mathrm{y}_{29.040 / \mathrm{SRPS} / 2008-2012.12}=-43 \mathrm{x}^{2}+204 \mathrm{x}+250$. 

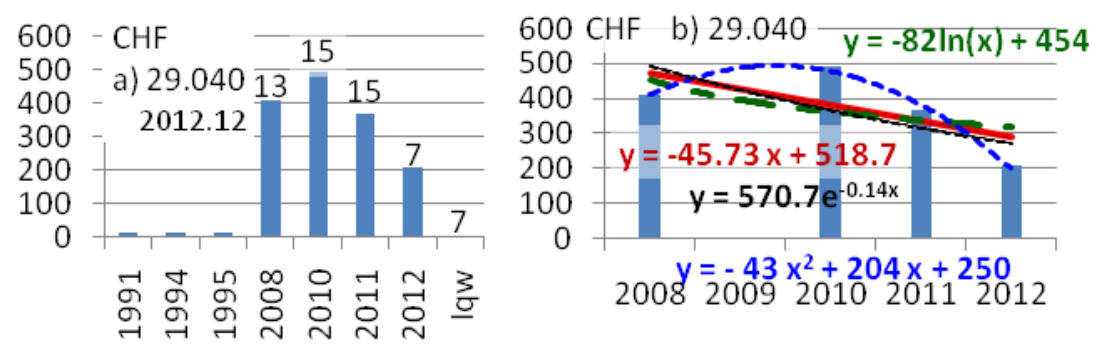

Figure 3

Analysis results for ICS_2 $=29.040$ - Insulating fluids - SRPS

\subsubsection{Subfield - Semiconducting Materials (29.045)}

Semiconducting materials subfield belongs to cluster I (Iqv = 1). This subfield has the fewest samples (Iqs $=1$ ). Other results are of no importance, because: a) the sample Iqs $/ 29.045 /$ SRPS $=1$ was developed in 2011 ; b) the trend of planned future needs is not displayed.

\subsubsection{Subfield - Superconductivity and Conducting Materials (29.050)}

Superconductivity and conducting materials subfield belongs to cluster I. There are no sub/subfields for ICS_3. Other results are not significant for the field of electrical engineering: a) with the aggregate sample available Iqs/29.050/sRPs $=15$ units from the period of 2004-2011; b) without the graph showing the trend of planned future needs according to (6.1):

$\mathbf{y}_{29.050 / S R P S / 2010-2011}=-371.8 x+773.4$.

\subsubsection{Subfield - Electrical Wires and Cables (29.060)}

Electrical wires and cables subfield belongs to cluster V (Iqv $=5$, along with subfield 10). Based on the levels classified according to ICS_3, some 350 samples are distributed as follows: 29.060.01 - Electrical wires and cables in general (1), 29.060.10 - Wires, including electric rods, busbars (141) and 29.060.20 - Cables (208).

The results of the analysis performed towards the end of 2012 are presented in Figure 4:

a) without currently valid standards dating back earlier than 1980 , the majority of samples being developed only over the past four years (2009-2012),

b) with regression lines and the anticipated trend of planned future (annual) needs, according to (7.1):

$\mathrm{y}_{29.060 / \mathrm{SRPS} / 2008-2012.12}=-390.7 \mathrm{x}^{2}+2605 \mathrm{x}-2020$. 

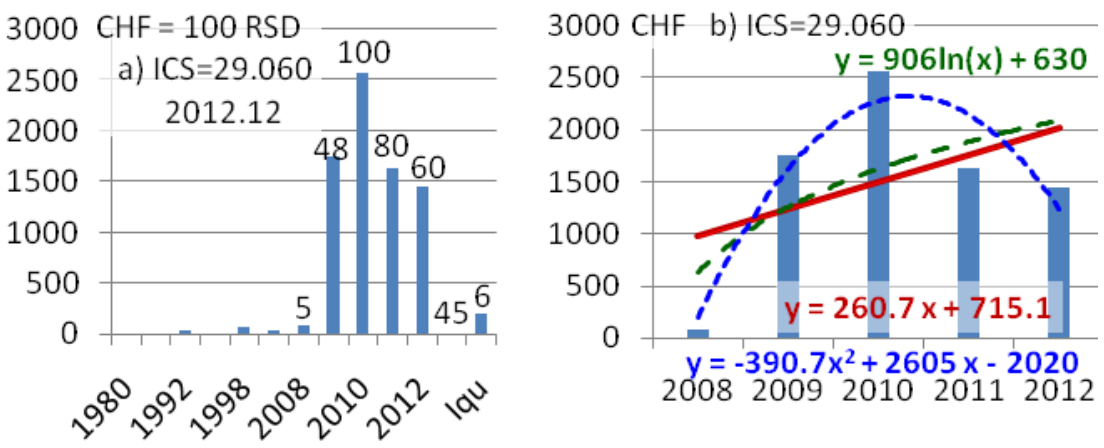

Figure 4

Analysis results for ICS_2 $=29.060$ - Electrical wires and cables - SRPS

\subsubsection{Subfield - Insulation, Insulating Fluids, Insulating Materials, Insulating Fluids (29.080)}

Insulation, insulating fluids, insulating materials subfield belongs to cluster III (along with subfields 13,14 and 15). The following subfields are related to this subfield: Insulating materials, see 29.035 and insulating fluids, see 29.040.

Samples available for analysis at this subfield level include 11 units, whereas the remaining 77 are distributed among levels classified according to ICS_3: 29.080.01 - Electrical insulation in general (15), 29.080.10 - Insulators, including fittings and other components for insulators (37), 29.080.20 - Bushings (10), 29.080.30 - Insulation systems (14), 29.080.99 - Other standards related to insulation (1). In this subfield, during early 2012 , Iqs $/ 29.080 /$ SRPS $=80$, two standards were under development, i.e. $\mathrm{Iqu}_{29.080 / \mathrm{SRPS}}=2$ (Ivu $\left.=39.45 \mathrm{CHF}\right), 2$ were withdrawn $\left(\mathrm{Iqw}_{29.080 / \mathrm{SRPS}}=2\right)$ and 76 were published, i.e. $\mathrm{Iqp}_{29.080 / \mathrm{SRPS}}=76$.
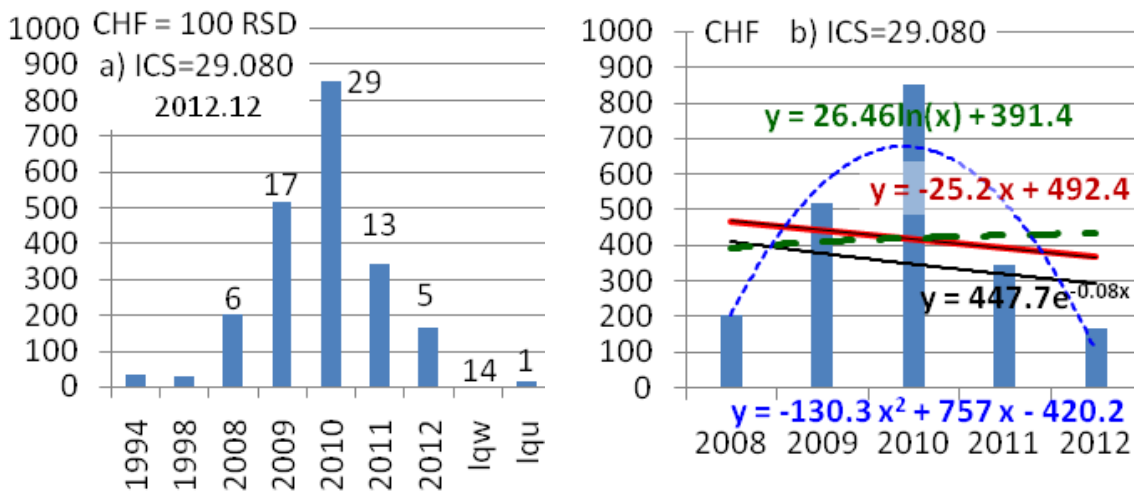

Figure 5

SRPS Analysis results for ICS_2 $=29.080$ - $\underline{\text { Insulation }}$ - SRPS 
Towards the end of 2012, the results of the analysis were slightly different, as shown in Figure 5, including: a) the aggregate analyses for the period 1994-2012; b) the trend of planned future (annual) needs according to (8.1) (Figure 5b):

$\mathrm{y}_{29.080 / \mathrm{SRPS} / 2008-2012.12}=-130.3 \mathrm{x}^{2}+757 \mathrm{x}-\mathbf{4 2 0 . 2}$.

\subsubsection{Subfield - Components for Electrical Equipment (29.100)}

Components for electrical equipment subfield belongs to cluster II (Iqv $=2$, along with 4, 16 and 19 subfields), including electronic components.

Figure $6 \mathrm{~b}$ shows the declining trend lines, while the anticipated trend line is $(9.1)$ :

$\mathrm{y}_{29.100 / \mathrm{SRPS} / 2008-2012}=-249.9 \mathrm{x}^{2}+1633 \mathrm{x}-2023$.

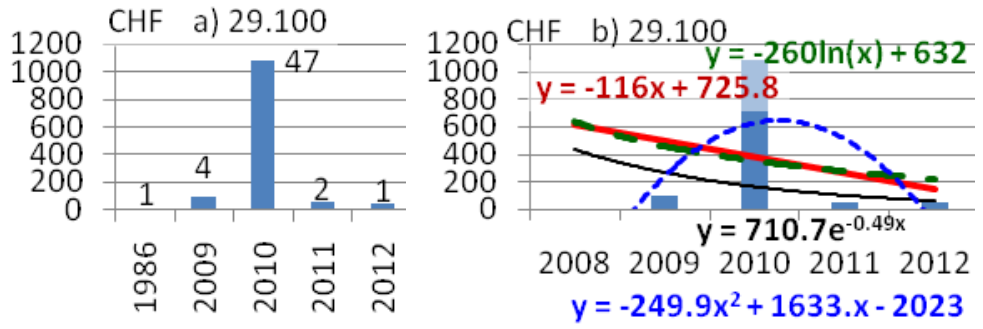

Figure 6

Analysis results for ICS_2 $=29.100$ - Components for electrical equipment - SRPS

The samples from this subfield include two units, while the remaining 53 are distributed among levels classified according to ICS_3: 29.100.01 - Components for electrical equipment in general (0), 29.100.10 - Magnetic components (52), 29.100.20 - Electric and electromechanical components (1), 29.100.99 - Other components for electrical equipment (0).

\subsubsection{Subfield - Electrical Accessories (29.120)}

Electrical accessories subfield belongs to cluster V (along with subfield 7).

Out of the overall sample in this subfield ( $\operatorname{Iqs}_{/ 29.120}$ ), only five units were derived before 2008, which is only about $2 \%$ (Figure 7a). Out of the four descending trend lines, the lowest and most realistic planned value is given by the polynomial relation (10.1).

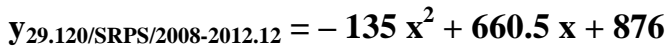




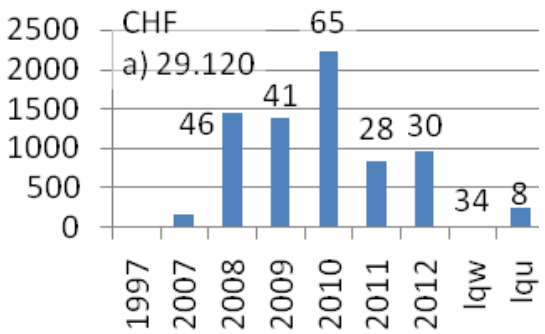

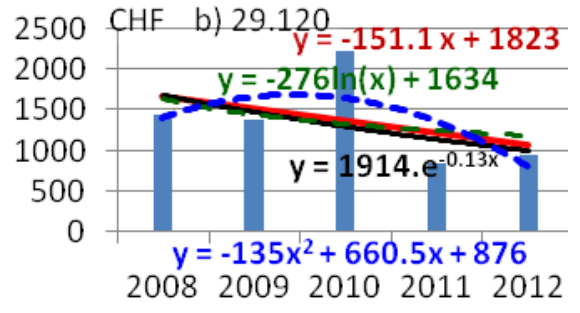

Figure 7

Analysis results for ICS_2 $=29.120$ - Electrical accessories - SRPS

Some 279 knowledge base units available are distributed among the levels classified according to ICS_3: 29.120.01 - Electrical accessories in general (6), 29.120.10 - Conduits for electrical purposes (31), 29.120.20 - Connecting devices (27), 29.120.30 - Plugs, socket-outlets, couplers (26), 29.120.40 - Switches (39), 29.120 .50 - Fuses and other over current protection devices (83), $29.120 .70-$ Relays (38), 29.120.99 - Other electrical accessories (18).

\subsubsection{Subfield - Switchgear and Controlgear (29.130)}

Switchgear and controlgear subfield belongs to cluster IV (Iqv $=4$, along with subfields 17 and 18). The analysis samples in this subfield include 14 units, while the remaining 105 units are distributed among levels classified according to ICS_3: 29.130.01 Switchgear and controlgear in general (0), 29.130.10 High voltage switchgear and controlgear, including enclosed switchgear and controlgear (33), 29.130.20 Low voltage switchgear and controlgear, including switchgear and controlgear assemblies (65), 29.130.99 Other switchgear and controlgear (7).

The sample or the overall population in these subfields was formed in 2008 and later (Figure 8a). Out of the declining trend lines, the closest is (11.1), given the small Iqu number:

$\mathrm{y}_{29.130 / \mathrm{SRPS} / 2008-2012.12}=-62 \mathrm{x}^{2}+346 \mathrm{x}+493$.

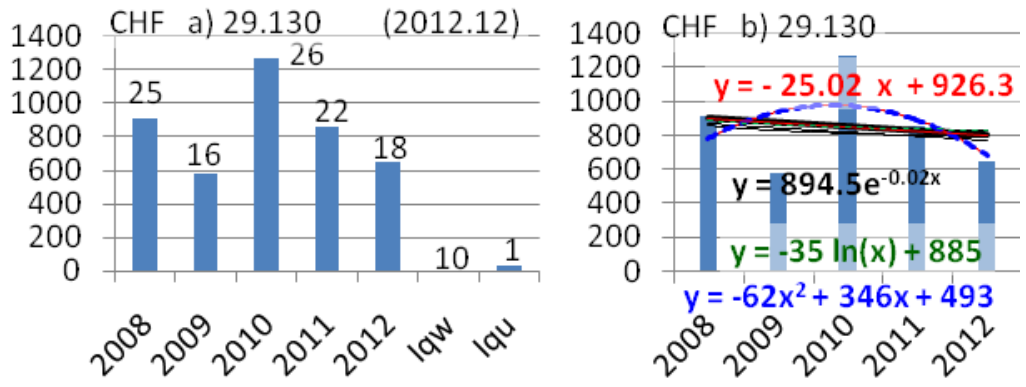

Figure 8

Analysis results for ICS_2 $=29.130-$ Switchgear and controlgear - SRPS 


\subsubsection{Subfield - Lamps and Related Equipment (29.140)}

Lamps and related equipment subfield belongs to cluster VII (Iqv = 7).

The results of the analysis are shown in Figure 9, including:

a) the aggregate analyses for the period 1984-2012, whereby only three units originated earlier than 2008 , which is less than $1 \%$,

b) the trend of the planned (annual) future needs based on the relation (12.1):

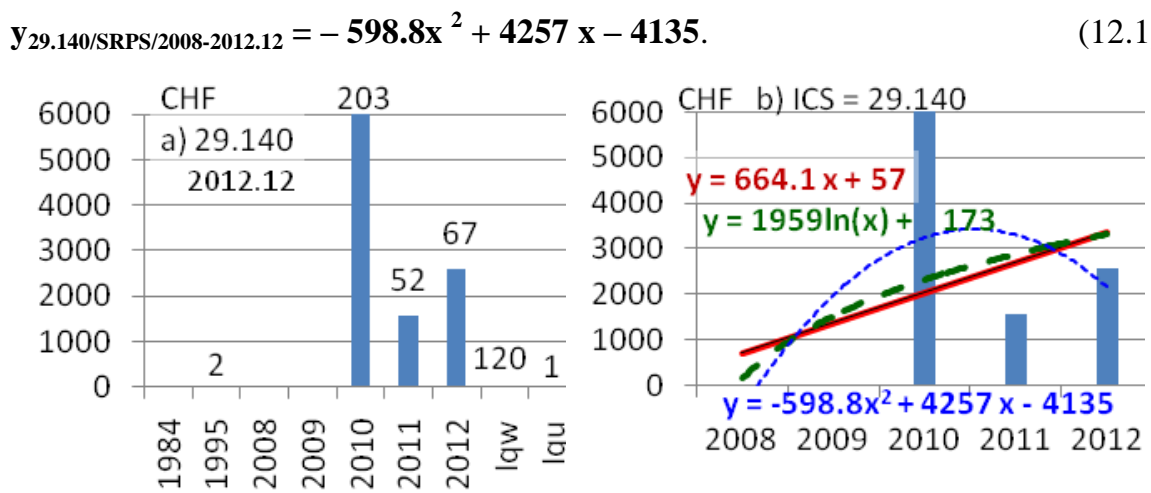

Figure 9

Analysis results for ICS_2 $=29.130$ - Lamps and related equipment - SRPS

Samples available for analysis within the respective subfield include seven units, whereas the remaining 441 are distributed among levels classified according to ICS_3, viz. 29.140.01 - Lamps in general (3), 29.140.10 - Lamp caps and holders (213), 29.140.20 - Incandescent lamps (43), 29.140.30 - Fluorescent lamps, discharge lamps (73), 29.140.40 - Luminaires (38), 29.140.50 - Lighting installation systems, including supply track systems (21), 29.140.99 - Other standards related to lamps (50).

Compared with all the other 18 subfields, this subfield records the highest values of the quantity index (this includes Iqs samples as well as the published Iqp $_{29.140 / S R P S}$ samples and the withdrawn Iqw $29.140 /$ SRPS samples), and the index value $\left(\mathrm{IV}_{/ 2011.11}, \mathrm{y}_{29.140 / \mathrm{SRPS} / 2013}\right)$.

\subsubsection{Subfield - Rotating Machinery (29.160)}

Rotating machinery subfield belongs to cluster III (along with subfields 8, 14 and 15). This subfield has the greatest number of analysis samples (45 units), whereas the remaining 29 are distributed among levels classified according to ICS_3: 29.160.01 - Rotating machinery in general (7), 29.160.10 - Components for rotating machines (4), 29.160.20 - Generators (4), 29.160.30 - Motors (7), 29.160.40 - Generating sets (6), 29.160.99 - Other standards related to rotating machinery (1). 
This subfield is the one with the highest quantity and value indices within the ISO standardization platform (see Table 1). The results of the analysis on the SRPS standardization platform are shown in Figure 10 with a) aggregate analyses for the 1992-2012 period, with only two units originating earlier than 2008, which is less than $3 \%$ (Figure 10a), and b) the clear downward trend of all the regression equations (Figure 10b), with the expected trend (13.1), given the significant development quantity of Iqu.

$\mathbf{y}_{\text {29.160/SRPS/2008-2012.12 }}=16 \mathrm{x}^{2}-185 \mathrm{x}+683$.
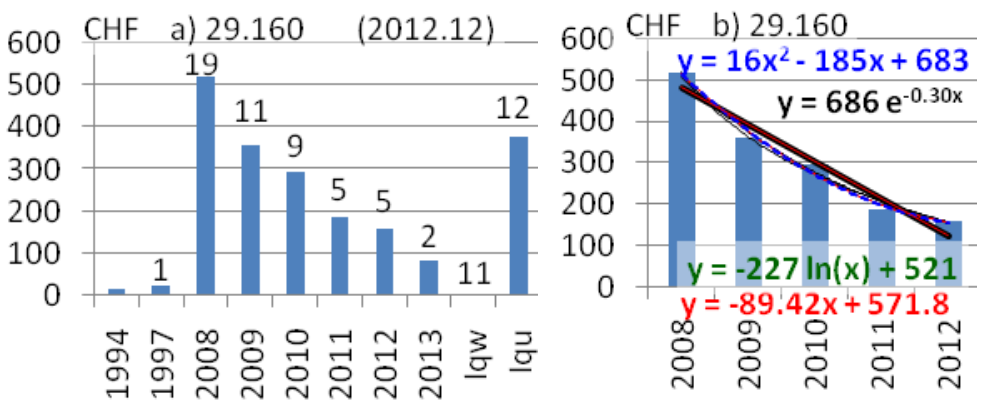

Figure 10

Analysis results for ICS_2 $=29.160$ - Rotating machinery - SRPS

\subsubsection{Subfield - Transformers, Reactors, Instrument Transformers (29.180)}

Transformers, reactors, instrument transformers subfield belongs to cluster III (along with subfields 8,13 and 15). The subfield is not subject to classification (in depth) at lower levels, and is related to instrument transformers (see 17.220.20). The results of the analysis on the SRPS standardization platform are shown in Figure 11 with:

a) the aggregate analyses for the period 1992-2012, whereby only one unit was developed before 2008 , which is less than $1 \%$,

b) the downward trend of all the regression equations and the most realistic one (14.1):

$\mathrm{y}_{29.180 / \mathrm{SRPS} / 2008-2012}=-103.1 \mathrm{x}^{2}+577.3 \mathrm{x}-116.6$. 


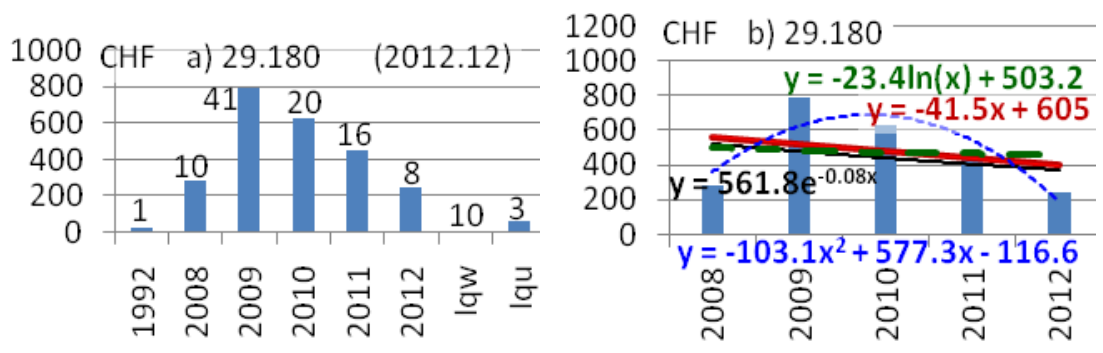

Figure 11

Analysis results for ICS_2 $=29.180$ - Transformers, Reactors, Instrument transformers - SRPS

\subsubsection{Subfield - Rectifiers, Converters, Stabilized Power Supply (29.200)}

Rectifiers, converters, stabilized power supply subfield belongs to cluster III (along with subfields 8,13 and 14). The subfield is not further classified (in depth) into sub/subfields, but it includes semiconductor converters.

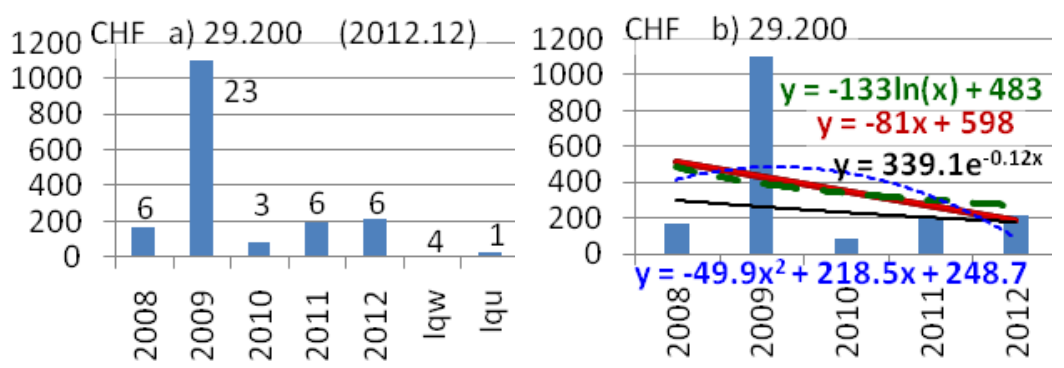

Figure 12

Analysis results for ICS_2 $=29.200$ - Rectifiers, Converters, Stabilized power supply - SRPS

The results of the analysis on the SRPS standardization platform are shown in Figure 12, with: a) the aggregate analysis for the period 2008-2012, whereby no valid units derived before 2008 are recorded (Figure 12a); b) the downward trend of all the regression equations (Figure 12b), along with the 'selection' of (15.1):

$\mathrm{y}_{29.200 / \mathrm{SRPS} / 2008-2012}=-49.9 \mathrm{x}^{2}+218.5 \mathrm{x}+248.7$.

\subsubsection{Subfield - Galvanic Cells and Batteries (29.220)}

Galvanic cells and batteries subfield belongs to cluster II (along with subfields 4, 9 and 19). Some 46 samples are classified among levels according to ICS_3, i.e., 29.220.01 - Galvanic cells and batteries in general (0), 29.220.10 - Primary cells and batteries (7), 29.220.20 - Acid secondary cells and batteries (26), 29.220.30 Alkaline secondary cells and batteries (9), 29.220.99 - Other cells and batteries (4). 
The results of the analysis are shown in Figure 13 with:

a) the aggregate analyses for the period 2000-2012, with only one unit produced earlier than 2008 ,

b) the downward trend of all the regression equations and the 'selection' of polynomial equation (16.1), which is the one closest to reality:

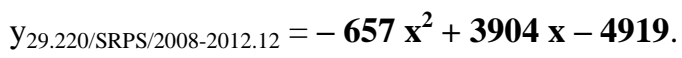

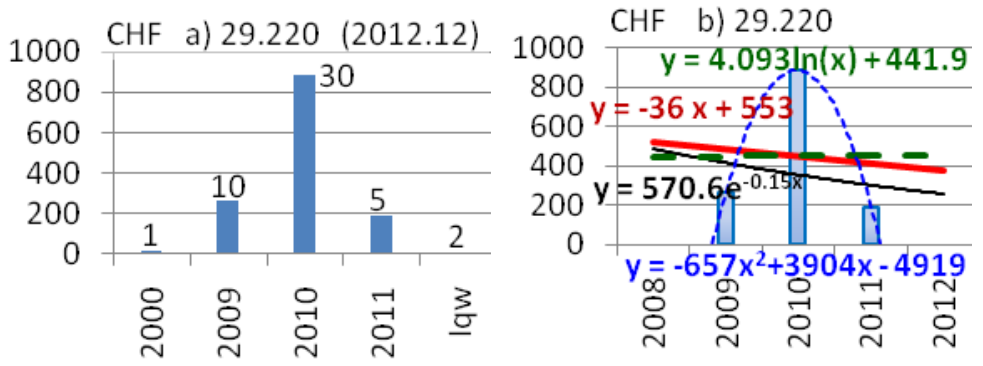

Figure 13

Analysis results for ICS_2 $=29.220-$ Galvanic cells and batteries - SRPS

\subsubsection{Subfield - Power Transmission and Distribution Networks (29.240)}

Power transmission and distribution networks subfield belongs to cluster IV (as well as subfields 11 and 18), and is related to electricity supply systems in buildings. At this subfield level 18 samples are available (for electricity supply systems in buildings), while the remaining 103 are distributed among lower levels classified according to ICS_3: 29.240.01 - Power transmission and distribution networks in general, power line telecommunications (13), 29.240.10 Substations, surge arresters (15), 29.240.20 - Power transmission and distribution lines (67), 29.240.30 - Control equipment for electric power systems, measuring instruments for electrical quantities (1), 29.240.99 - Other equipment related to power transmission and distribution networks, including capacitors for power networks (12).

The results of the analysis are shown in Figure 14 with:

a) the aggregate analyses for the period 1999-2012, whereby only two currently valid units were produced before 2008 , which is less than $2 \%$,

b) the growing trend of the regression equations and the 'selection' of the expected one (17.1):

$\mathrm{y}_{29.240 / \mathrm{SRPS} / 2008-2012.12}=-64.6 \mathrm{x}^{2}+564.9 \mathrm{x}-201.6$. 


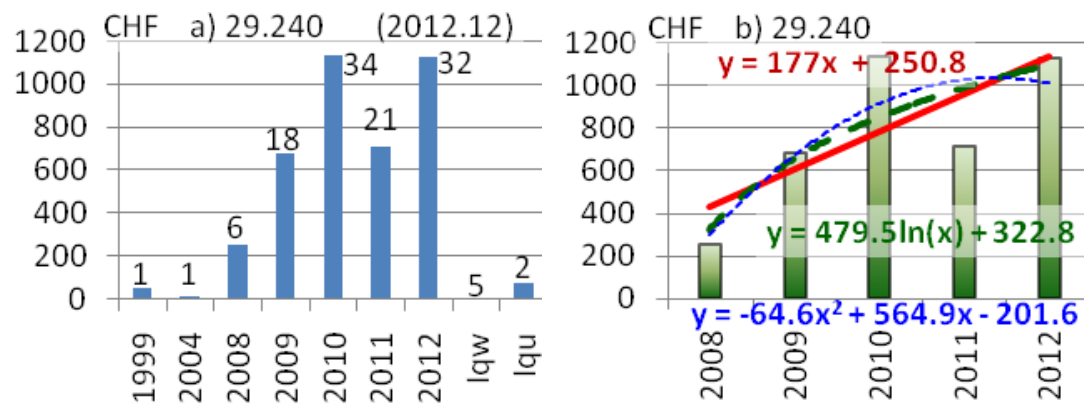

Figure 14

Analysis results for ICS_2 $=29.240$ - Power transmission and distribution networks - SRPS

\subsubsection{Subfield - Electrical Equipment for Working in Special Conditions (29.260)}

Electrical equipment for working in special conditions subfield belongs to cluster IV (as well as subfields 11 and 17). In this subfield, six samples are available, while the remaining 107 are distributed among lower levels classified according to ICS_3: 29.260.01 - Electrical equipment for working in special conditions in general (0), 29.260.10 - Electrical installations for outdoor use (2), 29.260.20 - Electrical apparatus for explosive atmospheres (69), 29.260.99 Other electrical equipment for working in special conditions (36).

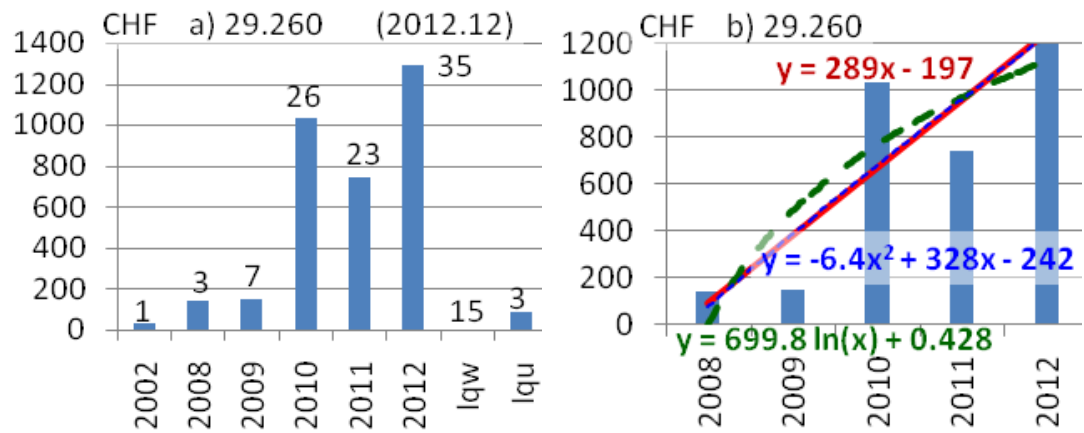

Figure 15

Analysis results for ICS_2 $=29.260$ - Electrical equipment for working in special conditions - SRPS

The results of the analysis are shown in Figure 15 with:

a) the aggregate analyses for the period 1999-2012, whereby only one currently valid unit was developed before 2008 , which is less than $1 \%$,

b) the growing trend of all the regression equations, and the 'selection' of (18.1):

$\mathrm{y}_{29.260 / \mathrm{SRPS} / 2008-2012.12}=699.8 \ln (\mathrm{x})+0.428$. 


\subsubsection{Subfield - Electric Traction Equipment (29.280)}

Electric traction equipment subfield belongs to cluster II (along with subfields 4, 9 and 16), including electric railway fixed installations, electric road vehicles, non-electric railway tractive stock. This subfield was not subject to further classification (in depth) into levels based on ICS_3.

The results of the analysis are shown in Figure 16 with:

a) the aggregate analyses for the period 1999-2012, whereby only two currently valid units were developed before 2008 , which is about $3 \%$,

b) the growing trend of the majority regression equations, except for (19.1):

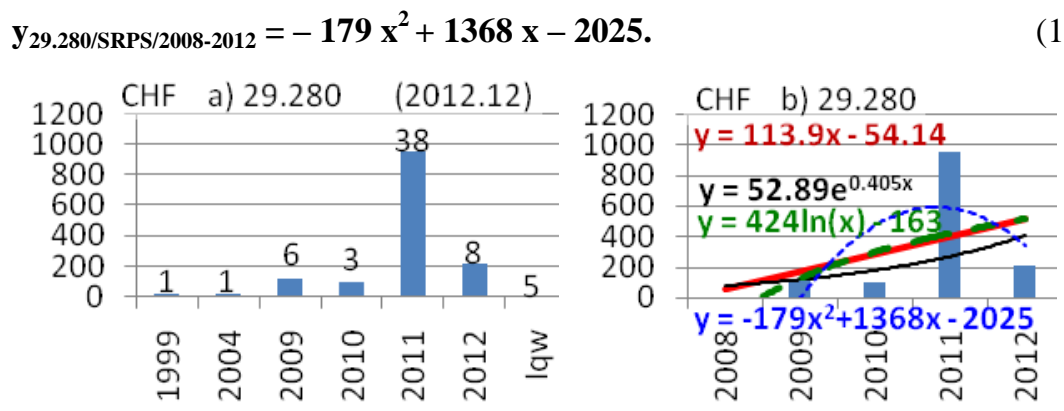

Figure 16

Analysis results for ICS_2 $=29.280-$ Electric traction equipment - SRPS

\section{Results and Discussion}

\subsection{Plan Phase Results (P)}

Based on the results presented above, one can predict future resources and financial needs for each of the subfields as well as for the entire field. This is ensured by the established mathematical relations (1) to (20), represented theoretically by the trend lines and practically by the defined Iv/year value indices, as well as the given information on the stages of new projects development (along with Iqu).

The correctness of the trend line is discussed in phase P. Although the field of electrical engineering has been extensively innovated by SRPS standards in recent years (due to Serbia's preparations for EU accession), this does not mean that the same trend will continue in the years ahead. Therefore, the deviation of selected regressions is high: (7.1), (8.1), (9.1), (10.1), (11.1), (12.1) to (19.1). 


\subsection{Do Phase Results (D)}

The results show significant 'index' issues in the analysed standardized knowledge base units among electrical engineering subfields. Figure 17a presents the specific results (Iv/year, Iqu) over 1980-2012 within the field analysed in its entirety (ICS_1 = 29). A negligible percentage of the currently valid knowledge base units were derived prior to 2008, the percentage being within the domain of statistical error.

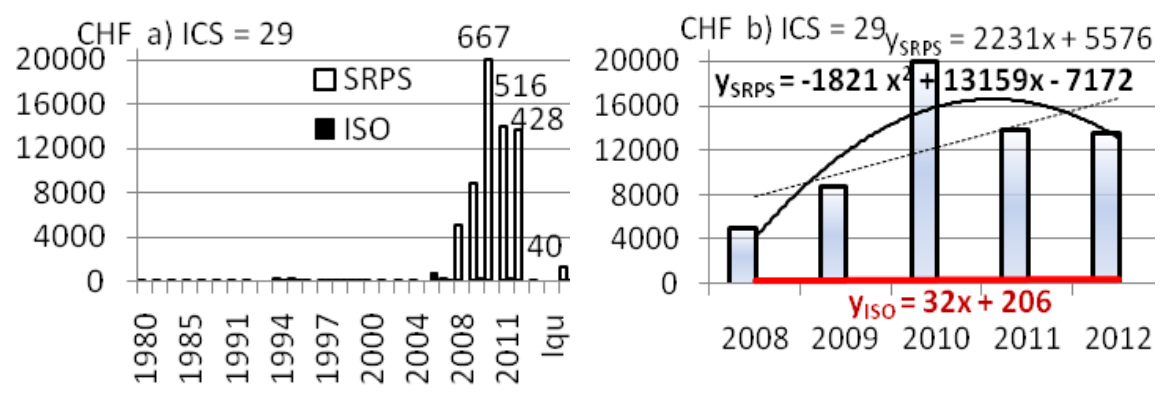

Figure 17

Examples of necessary resources and knowledge of all SRPS standards (ICS_1 = 29)

$\mathrm{y}_{\text {29/SRSP/2008-2011/P0 }}=-2386 \mathrm{x}^{2}+15343 \mathrm{x}-9370$,

$\mathrm{y}_{29 / 1 \mathrm{SO} / 2008-2011 / \mathrm{PO}}=\mathrm{y}_{29 / / \mathrm{ISO} / 2008-2012 / \mathrm{P} 1}=32 \mathrm{x}+206$.

\subsection{Check Phase Results $(C)$}

Compared with some other areas of human endeavour, such as IT (ICS_1 = 35), or IT applications in the industry subfield (ICS_2 = 25.040), the opposite trend in the SRPS to ISO ratio of numbers of standardized innovations is evident. There is a greater number of SRPS units than ISO units. Some 367 SRPS standards $\left(\mathrm{Iqu}_{/ \mathrm{SRPS} / 29 / 2012}\right)$ were developed in 2012 , i.e., more than one standard each day. As for ISO, no standards were developed in 2012, with only a few (5) pathways being developed in 2012, i.e., Iqu $_{/ / \mathrm{SO} / 29 / 2012}=5$.

The overall results provide the means to develop an authentic methodology for establishing appropriate relations with scientific fields and related teaching subjects at a higher education level. This is achieved by defining the ranking index (Iqv $=1,2,3$ to 7 ) as the criterion for grouping relevant subfields and/or fields of human endeavour into appropriate (teaching) groups [5].

Determining the index (or "degree") of innovation in the time dimension (Ity or It/year - per a year) is based on PDCA and defined values of quantity indices of development projects (Iqu), i.e., based on quantity indices of innovation (Iqi, phase Do). The period for checking innovations (Check) in certain fields or 
subfields is dependent on the time index of innovation, Ity. This index Ity is used to define groups or classes / clusters of innovation. The values of periodic checks (Check) on research for practice (1 - year, 2 - month, 3 - week or 4 - day) are assigned to this index. Ity $=1$, for $1 \leq \mathrm{Iqu}_{/ \mathrm{SRPS} / 2012} \leq 10$ (planned annual audits/ checks), for example, ICS_2 $=29.030,29.045,29.050$ etc (Iqv = 1, 2 and 3). Ity = 2 , for $10<\mathrm{Iqu}_{/ \mathrm{SRPS} / 2012} \leq 50$ (monthly Check, Table 1, column 8, Iqv = 4, 5 and 6). Ity $=3$, for $50<\mathrm{Iqu}_{/ \mathrm{SRPS} / 2012} \leq 250$ (weekly Check, Iqv $=6$ and 7), of the third class, which requires continuous weekly monitoring of innovations. Ity $=4$, for $\mathrm{Iqu}_{/ \mathrm{SRPS} / 2012}>250$ (daily Checks), for example, for ICS_1 = 29 is an example of the field, which requires continuous daily monitoring of innovations.

\subsection{Advancement Phase Results (A)}

The results show some important details of the analyses of the field of electrical engineering and its subfields, with the possibility of comparison between the existing concept of "the gap between individual and collective knowledge" according to [4] and "Learning Strategies and Styles..." according to [6].

A new PDCA cycle (designated as $\mathrm{P}_{1} \mathrm{D}_{1} \mathrm{C}_{1} \mathrm{~A}_{1}$ ) follows, with new plans for the next year (2013, Figure 17b) and the regression trend line based on (20.3):

$\mathrm{y}_{29 / \mathrm{SRPS} / 2008-2012 / \mathrm{P1}}=-1821 \mathrm{x}^{2}+13159 \mathrm{x}-7172$.

Solving this issue at the state level results in a national model of excellence in elearning, [7]. Future papers could deal with the incorporation of the high-ranking field of electrical engineering into the study curricula (concurrently with those in Europe and worldwide), and comparison of students' knowledge levels [8].

\section{Conclusions}

Based on the multicriteria analyses of knowledge units and the results presented through the examples of standardized electrical engineering subfields (ICS_1 = 29), and given also the confirmation of initial hypotheses, new conditions for future results/products have been provided.

1) According to the presented trends and dynamics of the development, original mathematical relations (1) to (20) have been derived and the trend lines have been presented. These provide an important theoretical aspect of the solution of the practical "problems".

2) Along with the analyses of knowledge base units in the field of electrical engineering, the correlation between local and international knowledge (SRPS to ISO) has been observed, whereas accessibility to individual teachers and associates in Serbia can be described as disputable.

3) The defined indices of quantity, value and ranking have enabled the comparisons above, as well as more efficient management of tasks and assignments related to respective scientific fields and related teaching subjects 
at the higher education level. The ranking of electrical engineering is the basis for future work in conjunction with the new study curricula.

4) There is an obvious relationship in the index value between annual and cumulative knowledge innovation, as well as the need for alternative solutions to the knowledge innovation developed on the basis of standardized units.

\section{Acknowledgement}

The work presented here was supported by the Ministry of Education and Science of the Republic of Serbia - project III 44006,

http://www.mi.sanu.ac.rs/projects/projects.htm\#Interdisciplinary

\section{References}

[1] Institute for Standardization of Serbia: Advanced search: http://www.iss.rs/, http://www.iss.rs/standard/advance_search.php (accessed: 01. 01. 2013)

[2] ISO: ISO Store, http://www.iso.org/iso/home/store/catalogue_ics.htm, 29: Electrical engineering (accessed: 01. 01.2013)

[3] P. B. Crosby, Quality is Free, McGraw-Hill (translated: Qualitass International, Beograd, 2010, p. 259)

[4] Ž. Micić, M. Demić, Knowledge Standardization in Road Vehicle Engineering, TTEM, Vol. 7, No. 3, 2012, 1281-1288

[5] Cluster Analysis, Ward's Method, (C) 2004 The Pennsylvania State University:

http://sites.stat.psu.edu/ ajw13/stat505/fa06/19_cluster/09_cluster_wards.ht $\mathrm{ml}$

[6] P. Tóth, Learning Strategies and Styles in Vocational Education, Acta Polytechnica Hungarica, Vol. 9, No. 2, 2012, 195-216

[7] Ž. Micić, M. Tufegdžić, Knowledge Management Modeling to e-learning Excellence, TTEM, Vol. 6, No. 4, 2011, 1333-1344

[8] G. Kiss, The Concept to Measure and Compare Students Knowledge Level in Computer Science in Germany and in Hungary, Acta Polytechnica Hungarica, Vol. 5, No. 4, 2008, 145-158 